\title{
Mending with Hard Tissue Augmentation: A Perioesthetic Approach
}

\author{
Ramaprabha Govindarajulu ${ }^{1}$, Navarasu Mathimaraiselvan², Pavithra R Seshadri ${ }^{3}$, Senthikumar Swaminathan ${ }^{4}$, \\ Lakshmisree Sankar ${ }^{5}$
}

\begin{abstract}
Background: Alveolar ridge deficiency can be due to many causes like infection, trauma, and tooth loss. This will create an anatomically unfavorable condition for the placement of implant-supported prosthesis, for which complete construction of alveolar bone with variable regenerative surgical procedures have become more accurate. This guided bone regeneration (GBR)-based surgical technique can be attempted either during implant placement or priorly to give proper restoration with longer and extensive prognosis.

Aim: This case report explains the hard tissue augmentation procedure with autogenous monocortical block bone graft harvested from the mandibular symphysis region.

Case description: A 22-year-old male patient came to the department of periodontics with a complaint of missing right central incisor for the past 2 months. On examination, Seibert's class III alveolar ridge deficiency with moderate depth was observed in the region of missing tooth. Conclusion: Augmentation of the height and width of the alveolar ridge defect (Seibert's class III ridge deficiency) using an autogenous chin graft has been applied in this patient. After few months, a significant increase in the area of the ridge defect was achieved.

Clinical significance: A combination of block graft obtained from the symphysis, along with osseous coagulum, is a predictable technique in augmenting atrophic ridge deficiency. It is still considered the gold standard compared with other grafting procedures. Ridge augmentation in the anterior region for this patient provided sufficient bone volume for implant placement as well as an esthetically satisfactory appearance. Keywords: Alveolar ridge augmentation, Block grafts, Osteotomy, Ridge defects.

International Journal of Experimental Dental Science (2019): 10.5005/jp-journals-10029-1196
\end{abstract}

\section{BACKGROUND}

Remodeling of residual alveolar ridge following loss of tooth is a common phenomenon. Following tooth extraction, the alveolar ridge diminishes in width and height rapidly, i.e., as much as $50 \%$ loss in bone width during the first year of extraction followed by two-thirds of which occurs in the initial 3 months. ${ }^{1}$

Different treatment modes have been described for restoring osseous form to enhance prosthetic rehabilitation. Some modes of treatment include guided bone regeneration (GBR) with or without particulate bone grafting, ridge splitting, distraction osteogenesis orthodontic tooth movement, grafting of bone blocks harvested intraorally, extra orally, or from allogeneic sources. ${ }^{2}$ Corticocancellous block grafts harvested from intraoral sites offer tremendous advantages in that they are biologically superior since the viable cancellous marrow cells transferred along with the marrow graft contribute to the bone regeneration at the recipient site. ${ }^{3}$

\section{Alveolar Ridge Defects Classification}

Seibert ${ }^{4}$ classified the ridge defects into three different categories:

- Class I defect: Buccolingual loss of tissue with normal height in apicocoronal dimension.

- Class II defect: Apicocoronal loss of tissue with normal ridge width in buccolingual dimension.

- Class III defect: Combination of buccolingual and apicocoronal loss of tissue resulting in loss of normal height and width.

Allen et al. $^{5}$ modified Seibert's classification by explaining the magnitude of ridge defect.

- Type I: Vertical ridge deficiency

- Type II: Horizontal ridge deficiency

- Type III: Combined horizontal and vertical ridge deficiency
1,4,5 Department of Periodontology, Rajah Muthiah Dental College and Hospital, Faculty of Dentistry, Annamalai University, Chidambaram, Tamil Nadu, India

${ }^{2}$ Department of Periodontology, Best Dental Science College, Madurai, Tamil Nadu, India

${ }^{3}$ Department of Periodontology, Ragas Dental College and Hospital, ECR, Uthandi, Chennai, Tamil Nadu, India

Corresponding Author: Ramaprabha Govindarajulu, Department of Periodontology, Rajah Muthiah Dental College and Hospital, Faculty of Dentistry, Annamalai University, Chidambaram, Tamil Nadu, India, Phone: +91 9245196777, e-mail: mailtoramaprabha@yahoo.com

How to cite this article: Govindarajulu R, Mathimaraiselvan N, Seshadri PR et al. Mending with Hard Tissue Augmentation: A Perioesthetic Approach. Int J Experiment Dent Sci 2019;8(2):58-62.

Source of support: Nil

Conflict of interest: None

The severity of ridge defect in comparison with the contour of the adjacent ridge is classified as follows:

- Mild: depth less than $3 \mathrm{~mm}$

- Moderate: depth ranging from $3 \mathrm{~mm}$ to $6 \mathrm{~mm}$

- Severe: depth more than $6 \mathrm{~mm}$

\section{Case Description}

A 22-year-old male patient reported with a chief complaint of missing right central incisor (11) for the past 2 months (Fig. 1). History of presenting illness revealed that the tooth was lost due to trauma 2 months back. The patient had no contributory medical or surgical history.

() The Author(s). 2019 Open Access This article is distributed under the terms of the Creative Commons Attribution 4.0 International License (https://creativecommons. org/licenses/by-nc/4.0/), which permits unrestricted use, distribution, and non-commercial reproduction in any medium, provided you give appropriate credit to the original author(s) and the source, provide a link to the Creative Commons license, and indicate if changes were made. The Creative Commons Public Domain Dedication waiver (http://creativecommons.org/publicdomain/zero/1.0/) applies to the data made available in this article, unless otherwise stated. 


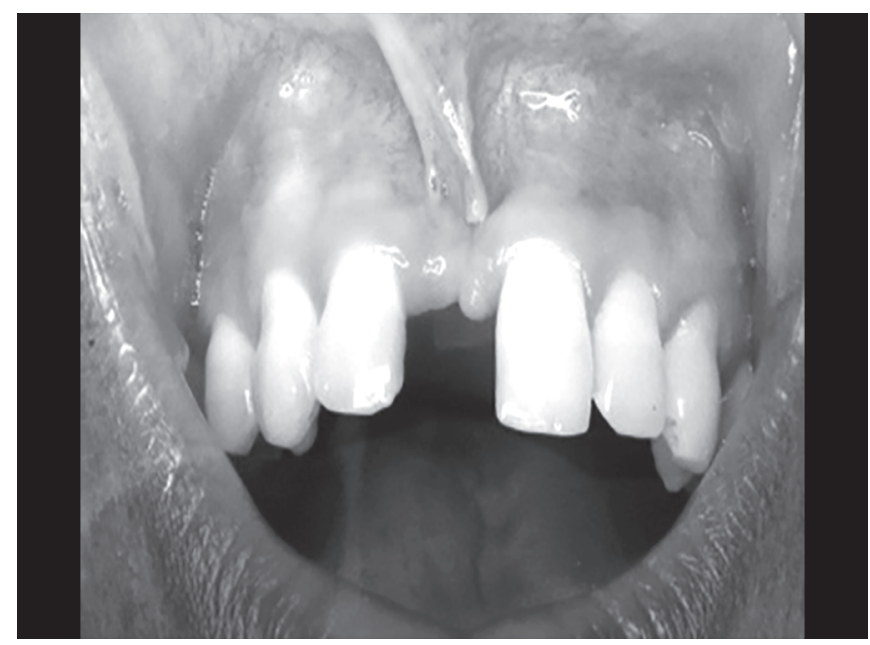

Fig. 1: Preoperative recipient site (11)

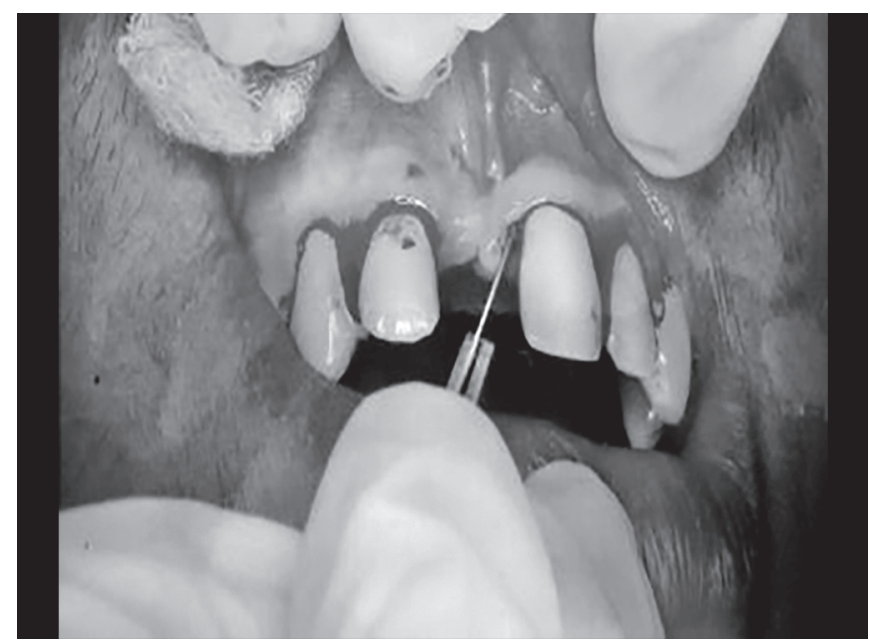

Fig. 3: Primary horizontal incision, sulcular incisions placed

Intraoral examination at baseline revealed a thick gingival biotype, associated with a favorable biological zone, maxillary labial frenum was of gingival type with a negative tension test, with adequate width of attached gingiva and vestibular depth, and intact interdental papilla, adjacent to the missing tooth.

Hard tissue examination revealed intact dentition with missing tooth 11 alone. Molars were in intact relationship. Bone sounding was done to measure the topography of hard tissue defect, and the dimensions were horizontally $4 \mathrm{~mm}$, vertically $8 \mathrm{~mm}$, and depth $3 \mathrm{~mm}$.

Assessment of all anatomic landmarks pertaining to the surgical site was carried out and recorded.

Radiographic examination of the adjacent tooth revealed no periapical pathology with normal periodontal ligament space. A mild radiolucency corresponding to missing tooth 11, suggestive of a defective labial plate, was observed (Fig. 2).

\section{Surgical Procedure}

\section{Preparation of Recipient Site}

Under profound local anesthesia, a primary sulcular incision was carried out in relation to teeth 12, 21 and was outlined by two vertical releasing incisions in relation to teeth 12, 21 (Fig. 3). A full thickness along with partial thickness flap was reflected facially

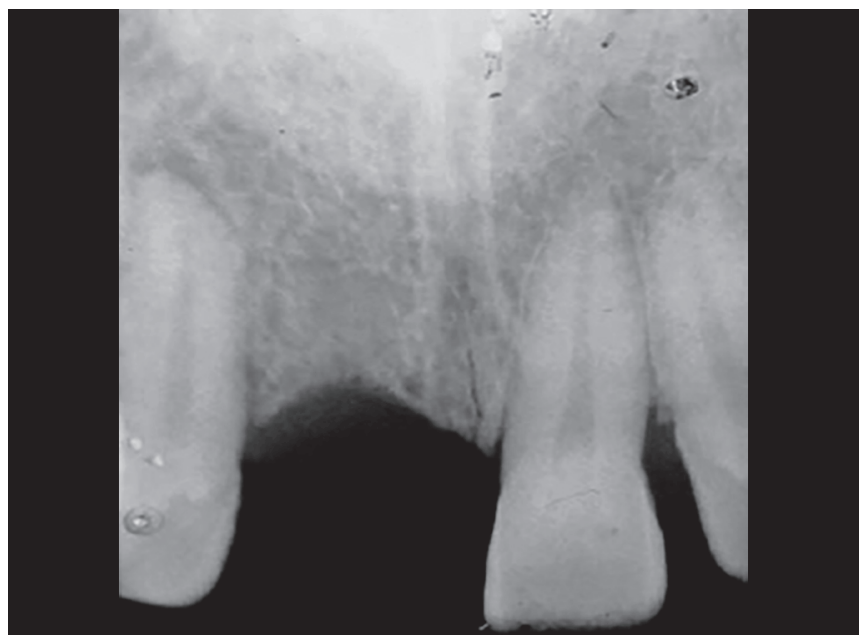

Fig. 2: Preoperative radiograph of Figure 1

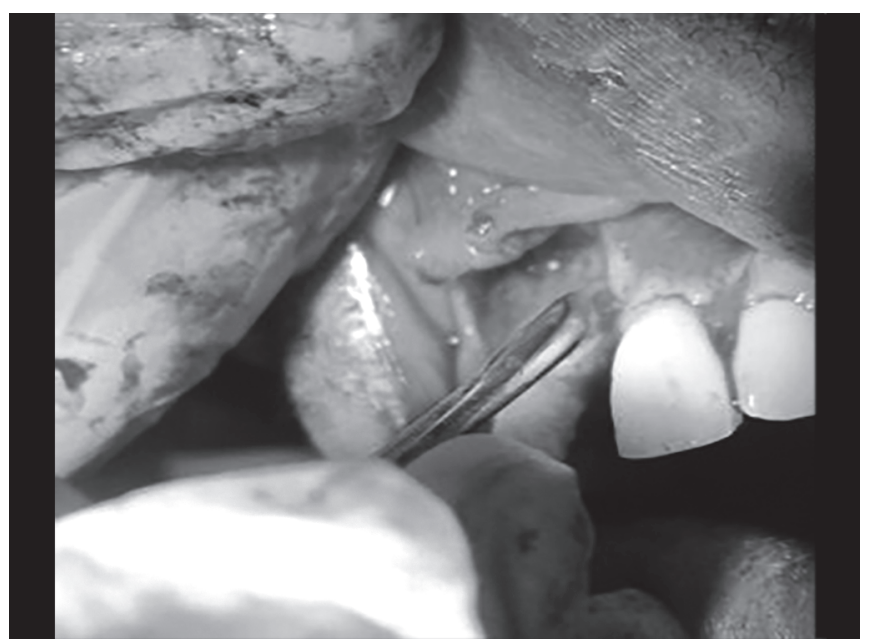

Fig. 4: Blunt incision placed

including about $6 \mathrm{~mm}$ of palatal tissue at the line angle of adjacent teeth including the facial flap.

Blunt dissection was performed using periosteal elevator up to $5 \mathrm{~mm}$ beneath the base of the defect followed by elevation of partial thickness flap using $15 \mathrm{C}$ blade (Fig. 4). Periosteal releasing incision was given at the base of the partial thickness flap to mobilize the flap.

\section{Preparation of Graft Site}

Following surgical access of the recipient site, decortications of the cortical bone was carried for better vascular anastomosis following grafting and a surgical template was made (Figs 5 and 6).

\section{Preparation of Donor Site}

Area apical to right lower central incisor and canine was chosen to procure monocortical bone graft following radiographic assessment (Fig. 7).

Under profound anesthesia, a beveled incision (vestibule) was made with no. 15 scalpel at least $6 \mathrm{~mm}$ beyond mucogingival junction (MGJ) extending mesiodistally in the donor site (Fig. 8). Incision extended bilaterally to the cuspids, limiting the distal extent to reduce the incidence of mental nerve paresthesia and the mucoperiosteal flap reflected (Fig. 9). 


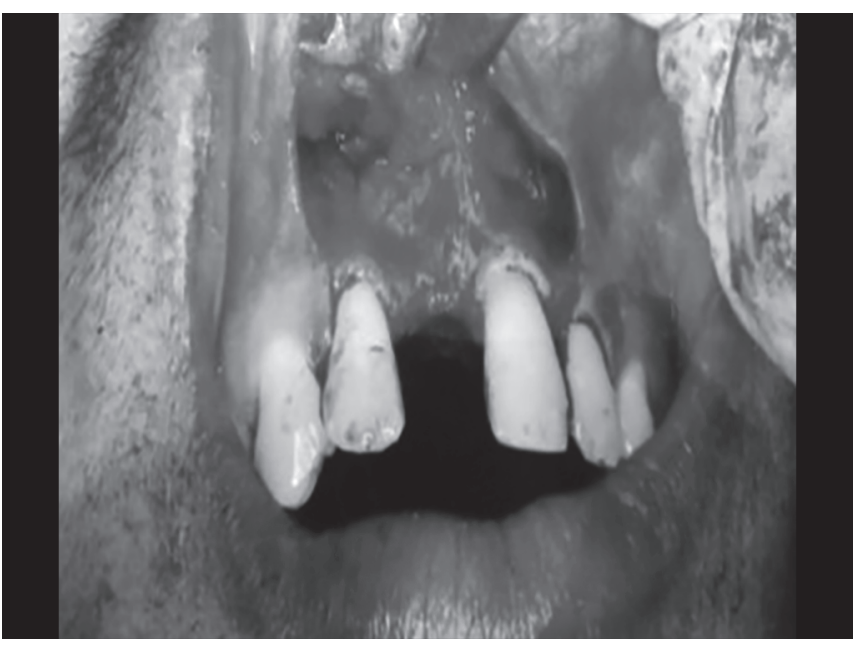

Fig. 5: Decortication of cortical bone

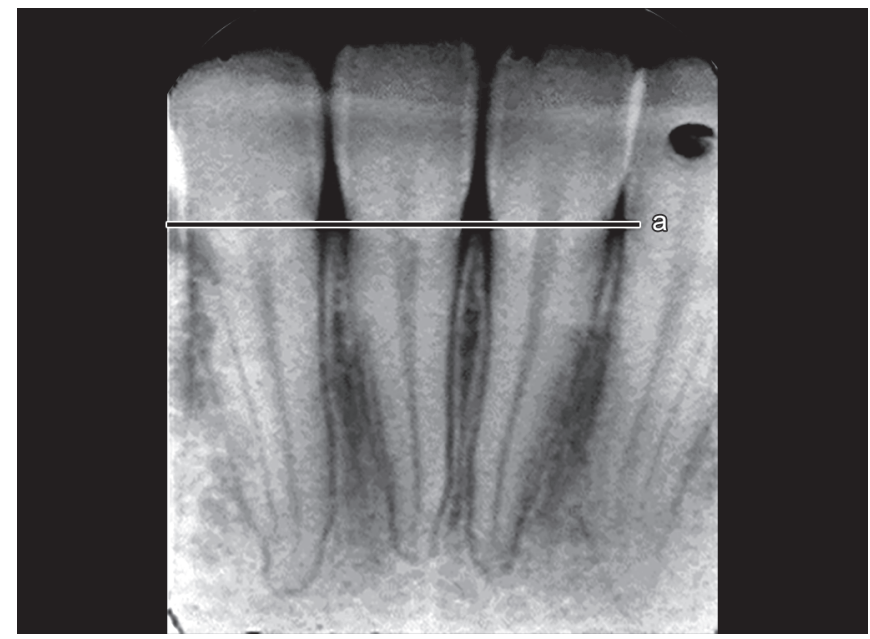

Fig. 7: Preoperative radiograph of donar site

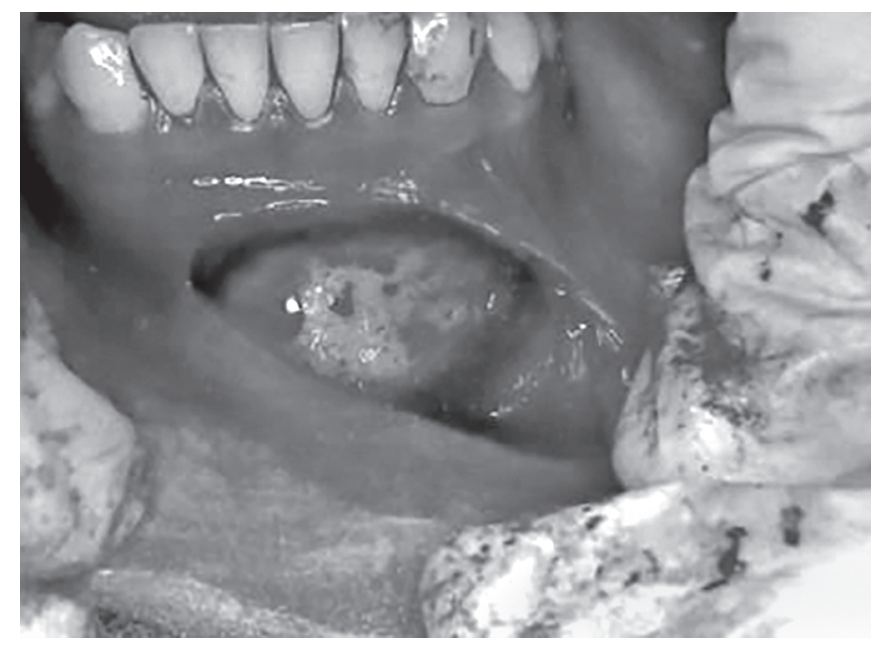

Fig. 9: Mucoperiosteal flap reflected

Using surgical template, a surgical outline was made apical to the root apex of the right lower anterior for the proposed ostectomy (Fig. 10). Following surgical guide, a monocortical bone graft of desired dimension was harvested and stored under saline.

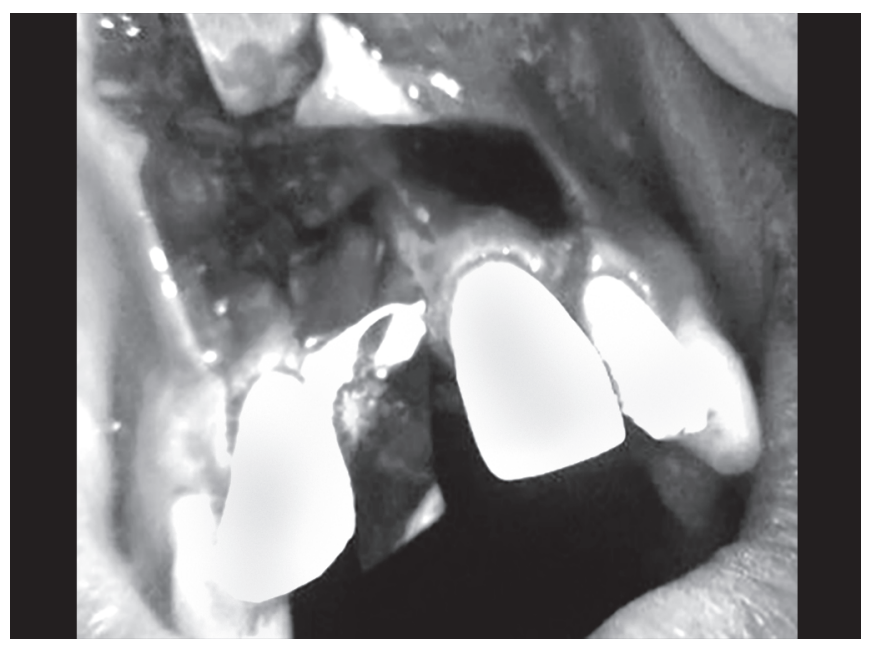

Fig. 6: Surgical template prepared

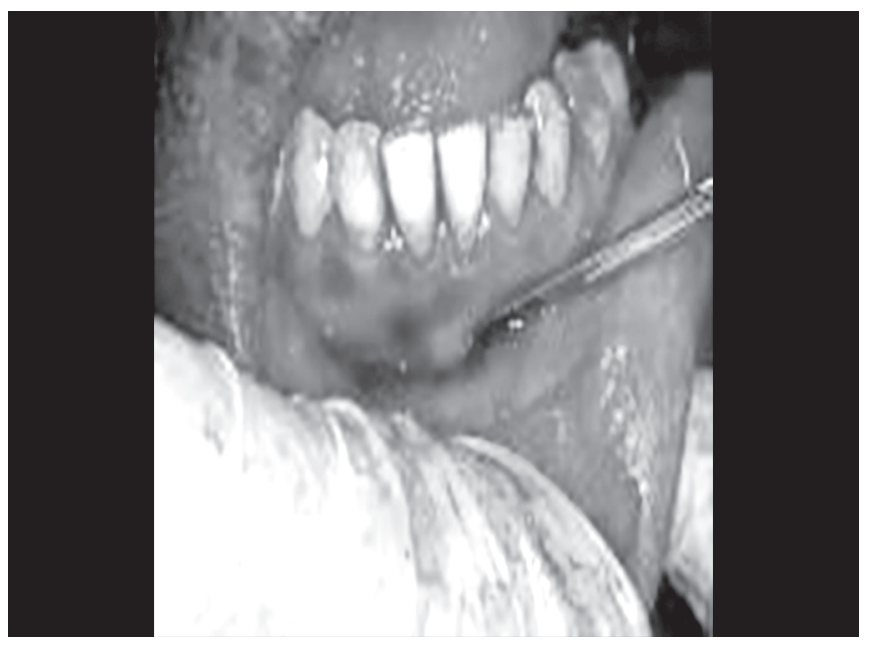

Fig. 8: Vestibular incisions placed

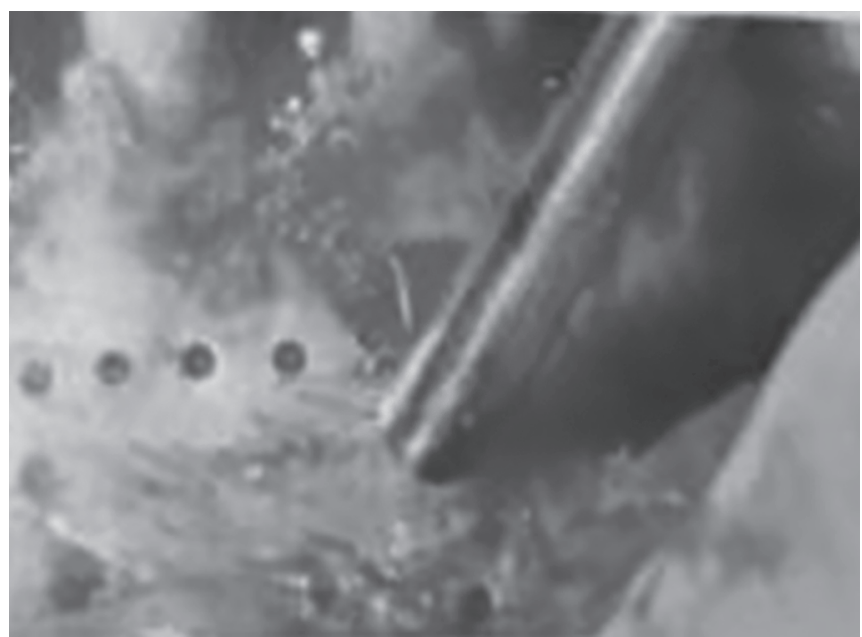

Fig. 10: Outline created around template

In the donor site, an outline was marked around the template to obtain the exact size of block graft. Round holes were driven to serve as depth cuts (thickness of cortical plate). A surgical outline was made for the proposed ostectomy corresponding to the extent 


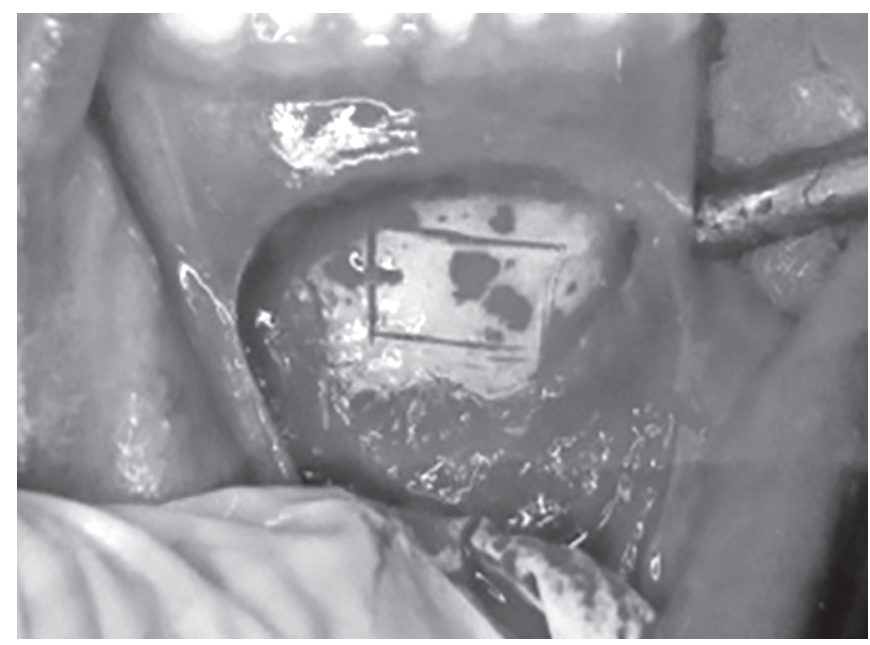

Fig. 11: Superior and inferior osteotomy done

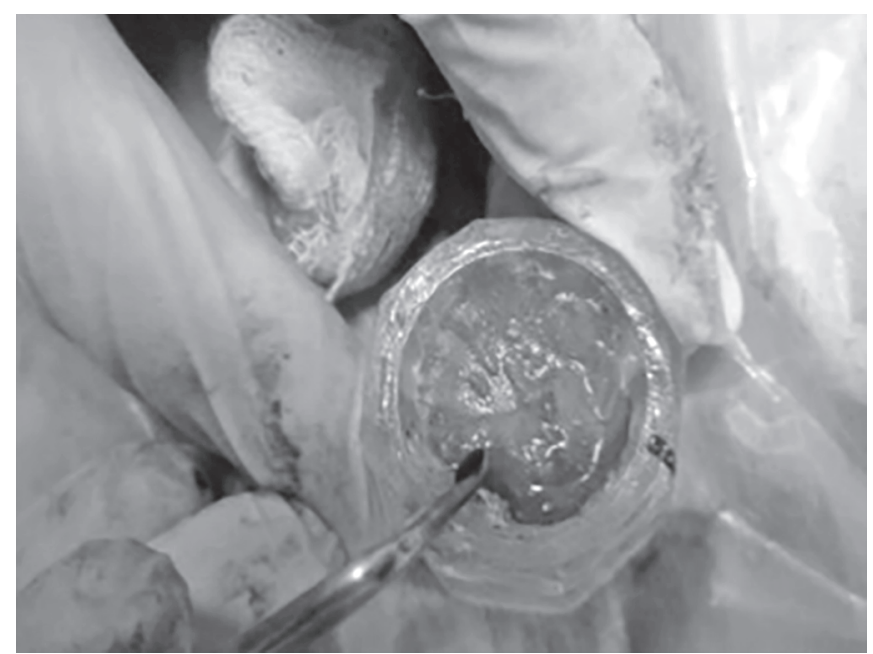

Fig. 13: Bone coagulum mixed

of bone to be harvested with the aid of surgical template using a piezotome $5 \mathrm{~mm}$ apical to the root apex of the lower incisor following surgical guidelines. Superior osteotomy cuts were made $-5 \mathrm{~mm}$ below apices of teeth. Round depth holes extending through outer cortex were connected using piezotome under copious irrigation. Inferior osteotomy was performed superior to inferior border of mandible (Fig. 11).

The bone block was lifted with angled chisel $45^{\circ}$ (Fig. 12). Block graft and cancellous bone were placed in sterile saline for maintaining the viability.

Bone coagulum was prepared by scraping the cancellous bone in the donor site which was mixed with patient's own blood to fill the residual spaces (Fig. 13).

The harvested cortical bone graft was then surgically transferred to the recipient bed and stabilized using 3-mm stainless steel screw at the center of the defect using micromotor drills, under copious saline irrigation (Fig. 14).

\section{Closure of the Sites}

\section{Donor Site}

The donor area was protected with collagen membrane. The flap was approximated and closed by primary closure.

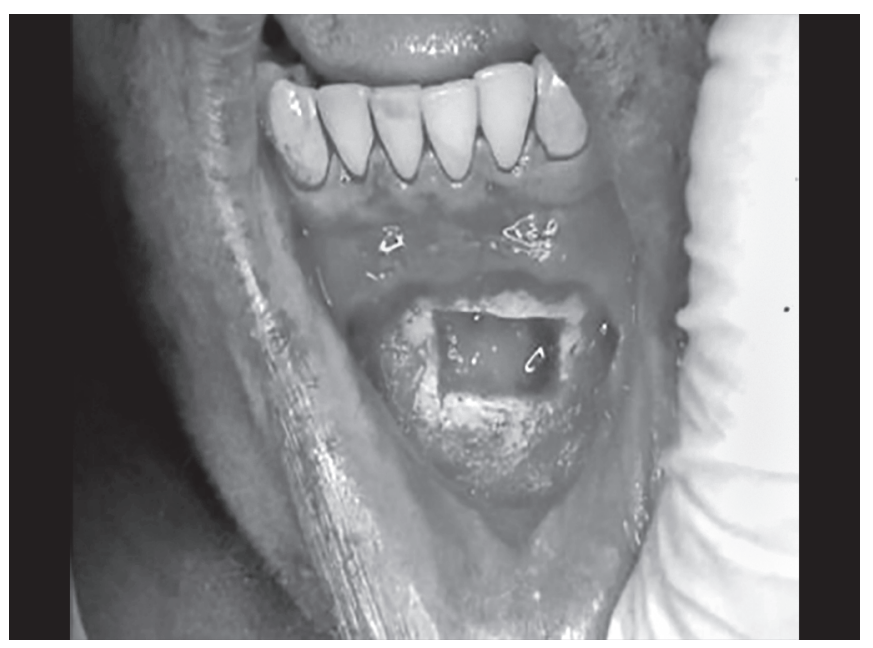

Fig. 12: Graft harvested

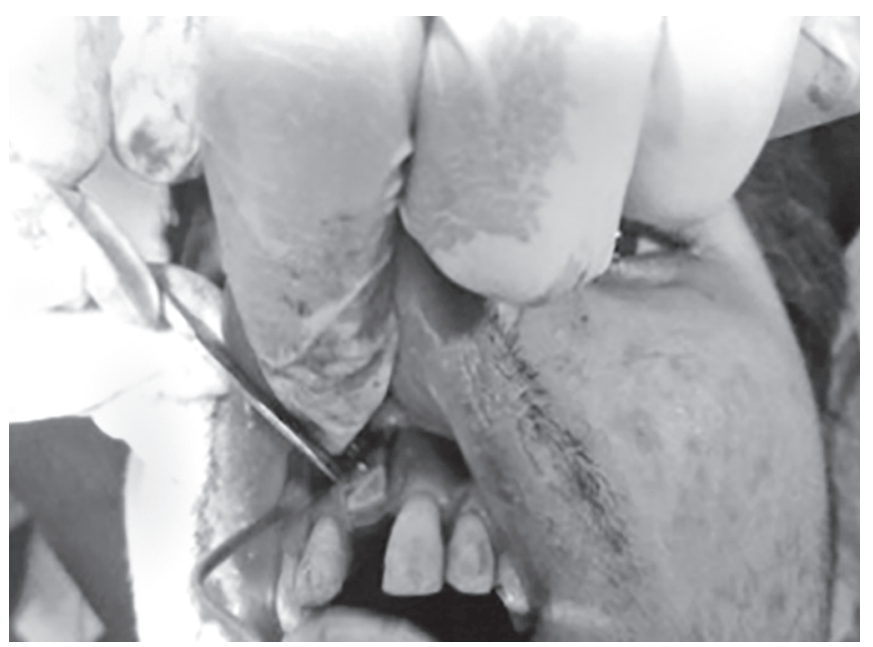

Fig. 14: Block graft stabilized in the recipient site with fixation screws

Mucosal flap was sutured separately using 4.0 interrupted sutures. Periodontal dressing was placed.

\section{Recipient Site}

The flaps were approximated and closed by interrupted sutures, and the surgical site was protected with periodontal dressing.

\section{Postoperative Maintenance}

Medications were prescribed to control the postoperative complications. Amoxicillin $500 \mathrm{mg}$ and metronidazole $400 \mathrm{mg}$ three times daily were given for 5 days. Anti-inflammatory analgesic combiflam (ibuprofen $400 \mathrm{mg}$ + paracetamol $500 \mathrm{mg}$ ) was also prescribed. A periodic review was done. Sutures and pack were removed after 14 days. The postoperative radiograph showed an increase in bone height after augmentation (Fig. 15).

\section{Discussion}

Even though intraoral and extra oral harvesting procedures are available, intraoral sites have been preferred for treating the localized atrophic defects in partially edentulous jaws. ${ }^{6}$ The main drawback of using autogenous bone grafts is the morbidity with the harvesting procedure. Intraorally, the donor sites includes the chin 


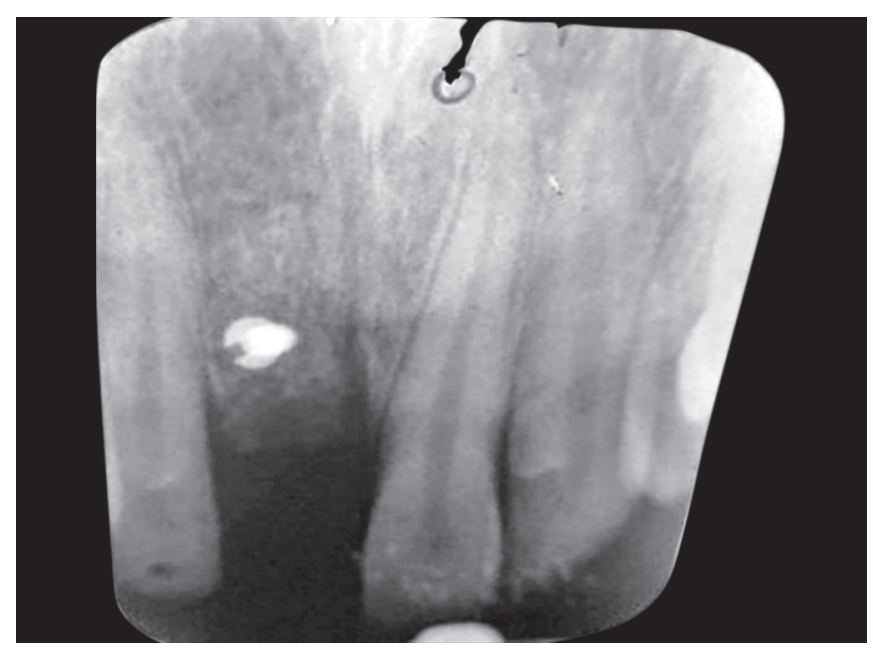

Fig. 15: Three-months postoperative radiograph

and the retromolar region in the mandible. Moreover, the intraoral harvesting procedures also have some drawbacks such as limited availability of bone grafts, postoperative complications including altered sensation of teeth, neurosensory disturbances, wound dehiscences, and infection. ${ }^{8}$ In comparison with the other bone graft materials, autogenous bone graft material is considered the best because it is osteogenic, along with being osteoconductive. Most likely, there is no risk of rejection or adverse reaction to the graft material when it is autogenous. ${ }^{9}$

\section{Conclusion}

This article presents a case report of alveolar ridge augmentation in a partially edentulous patient prior to implant placement, using autogenous bone graft harvested from the mandibular symphysis which has been firmly secured to the recipient site with osteosynthesis screws. The outcome of this treatment gave a promising and good improvement in the atrophic ridge defect.

\section{Clinical Significance}

The clinical indication for autogenous bone graft in this patient was the deficient alveolar bone quantity which could compromise the esthetics along with interference in the functional loading of implants. The symphysis block bone graft has given an excellent outcome within a short healing time and has provided an ideal site for endosseous implant placement.

\section{References}

1. Schropp L, Wenzel A, Kostopoulos L, et al. Bone healing and soft tissue contour changes following single-tooth extraction: a clinical and radiographic 12-month prospective study. Int J Periodont Rest Dent 2003;23(4):313-323.

2. Toscano N, Shumaker N, Holtzclaw D. The art of block grafting. A review of the surgical protocol for reconstruction of alveolar ridge deficiency. J Imp \& Adv Cli Dent 2010;2(2):45-66.

3. Durrani Farhan. Bone augmentation using autogenous block grafts and particulate bovine bone in the severe atrophic ridges: case reviews. Int J Contemp Dent and Med Rev 2016. 1-4.

4. Seibert JS. Reconstruction of deformed, partially edentulous ridges, using full thickness onlay grafts. part I. Technique and wound healing. Compend Contin Educ Dent 1983;4(5):437-453.

5. Allen EP, Gainza CS, et al. Improved technique for localized ridge augmentation: a report of 21 cases. J Periodontol 1985;56(4):195-199. DOI: 10.1902/jop.1985.56.4.195.

6. Joshi A, Kostakis GC. An investigation of post-operative morbidity following iliac crest bone harvesting. Br Dent J 2004;196(3):169-171. DOI: 10.1038/sj.bdj.4810945.

7. Nkenke E, Schultz-Mosgau S, Radespiel-Tröger M, et al. Morbidity of harvesting of chin grafts: a prospective study. Clin Oral Implants Res 2001;12(5):495-502. DOI: 10.1034/j.1600-0501.2001.120510.x.

8. Von Arx T, Hafliger J, Chappuis V. Neurosensory disturbances following bone harvesting in the symphysis: a prospective clinical study. Clin Oral Implants Res 2005;16(4):432-493. DOI: 10.1111/j.16000501.2005.01138.x.

9. Erikkson RA, Albrektsson T. The effect of heat on bone regeneration: an experimental study on the rabbit using the bone growth chamber. J Oral Maxillofac Surg 1984;42(11):705-711. DOI: 10.1016/02782391(84)90417-8. 